\title{
Associations Between Social Vulnerabilities and Psychosocial Problems in European Children Results from the IDEFICS Study
}

Iguacel, Isabel; Michels, Nathalie; Fernández-Alvira, Juan M.; Bammann, Karin; De Henauw, Stefaan; Felső, Regina; Gwozdz, Wencke; Hunsberger, Monica; Reisch, Lucia; Russo, Paola; Tornaritis, Michael; Thumann, Barbara Franziska; Veidebaum, Toomas; Börnhorst, Claudia; Moreno, Luis A.; On behalf of the IDEFICS consortium

Document Version

Accepted author manuscript

Published in:

European Child and Adolescent Psychiatry

DOI:

10.1007/s00787-017-0998-7

Publication date:

2017

License

Unspecified

Citation for published version (APA):

Iguacel, I., Michels, N., Fernández-Alvira, J. M., Bammann, K., De Henauw, S., Felső, R., Gwozdz, W., Hunsberger, M., Reisch, L., Russo, P., Tornaritis, M., Thumann, B. F., Veidebaum, T., Börnhorst, C., Moreno, L. A., \& On behalf of the IDEFICS consortium (2017). Associations Between Social Vulnerabilities and Psychosocial Problems in European Children: Results from the IDEFICS Study. European Child and Adolescent Psychiatry, 26(9), 1105-1117. https://doi.org/10.1007/s00787-017-0998-7

Link to publication in CBS Research Portal

\section{General rights}

Copyright and moral rights for the publications made accessible in the public portal are retained by the authors and/or other copyright owners and it is a condition of accessing publications that users recognise and abide by the legal requirements associated with these rights.

Take down policy

If you believe that this document breaches copyright please contact us (research.lib@cbs.dk) providing details, and we will remove access to the work immediately and investigate your claim. 


\section{Associations Between Social Vulnerabilities and Psychosocial Problems in European Children: Results from the IDEFICS Study}

Isabel Iguacel, Nathalie Michels, Juan M. Fernández-Alvira, Karin Bammann, Stefaan De Henauw, Regina Felső, Wencke Gwozdz, Monica Hunsberger, Lucia Reisch, Paola Russo, Michael Tornaritis, Barbara Franziska Thumann, Toomas Veidebaum, Claudia Börnhorst, Luis A. Moreno, On behalf of the IDEFICS consortium

Journal article (Accepted version)

CITE: Iguacel, I., Michels, N., Fernández-Alvira, J. M., Bammann, K., De Henauw, S., Felső, R., ... On behalf of the IDEFICS consortium (2017). Associations Between Social Vulnerabilities and Psychosocial Problems in European Children: Results from the IDEFICS Study. European Child and Adolescent Psychiatry, 2699), 11051117. 001: 10.1007/s00787-017-0998-7

This is a post-peer-review, pre-copyedit version of an article published in International Journal of Public Health. The final authenticated version is available online at: https://doi.org/10.1007/s00787-017-0998-7

Uploaded to CBS Research Portal: January २०19 
Associations between social vulnerabilities and psychosocial problems in European children. Results from the IDEFICS study.

Isabel Iguacel ${ }^{1,2,3^{*}}$, Nathalie Michels ${ }^{4}$, Juan M. Fernández-Alvira ${ }^{1,5}$, Karin Bammann ${ }^{6,7}$, Stefaan De Henauw $^{4}$, Regina Felső ${ }^{8}$, Wencke Gwozdz ${ }^{9}$, Monica Hunsberger ${ }^{10}$, Lucia Reisch $^{9}$, Paola Russo $^{11}$, Michael Tornaritis $^{12}$, Barbara Franziska Thumann ${ }^{7}$, Toomas Veidebaum ${ }^{13}$, Claudia Börnhorst ${ }^{7,15}$, Luis A. Moreno $^{1,2,3,14,15}$ on behalf of the IDEFICS consortium

${ }^{1}$ GENUD (Growth, Exercise, NUtrition and Development) Research Group, Faculty of Health Sciences; University of Zaragoza, Edificio del SAI, C/Pedro Cerbuna s/n, 50009 Zaragoza, Spain

${ }^{2}$ Instituto Agroalimentario de Aragón (IA2), Zaragoza, Spain

${ }^{3}$ Instituto de Investigación Sanitaria Aragón (IIS Aragón), Zaragoza, Spain

${ }^{4}$ Department of Public Health, Ghent University, Ghent, Belgium

${ }^{5}$ Fundación Centro Nacional de Investigaciones Cardiovasculares Carlos III (CNIC), Madrid, Spain

${ }^{6}$ Institute for Public Health and Nursing Sciences (IPP), University of Bremen, Bremen, Germany

${ }^{7}$ Leibniz Institute for Prevention Research and Epidemiology - BIPS, Bremen, Germany

${ }^{8}$ Department of Paediatrics, University of Pécs, Pécs, Hungary

${ }^{9}$ Copenhagen Business School, Copenhagen, Denmark

${ }^{10}$ Section for Epidemiology and Social Medicine (EPSO), Sahlgrenska Academy, University of Gothenburg, Gothenburg, Sweden

${ }^{11}$ Institute of Food Sciences, National Research Council, Avellino, Italy

${ }^{12}$ Research and Education Institute of Child Health, Strovolos, Cyprus

${ }^{13}$ Department of Chronic Diseases, National Institute for Health Development, Tallinn, Estonia

${ }^{14}$ Centro de Investigación Biomédica en Red de Fisiopatología de la Obesidad y Nutrición (CIBERObn), Zaragoza, Spain

${ }^{15}$ These authors contributed equally and share the last authorship.

* Corresponding author: I. Iguacel, phone +34 876553753 email iguacel@ unizar.es

Keywords: vulnerable groups: psychosocial problems: well-being: internalising problems: inequalities: children 


\section{Abstract}

The effect of socioeconomic inequalities on children's mental health remains unclear. This study aims to explore the cross-sectional and longitudinal associations between social vulnerabilities and psychosocial problems, and the association between accumulation of vulnerabilities and psychosocial problems. 5987 children aged 2-9 years from eight European countries were assessed at baseline and two-year followup. Two different instruments were employed to assess children's psychosocial problems: the KINDL (Questionnaire for Measuring Health-Related Quality of Life in Children and Adolescents) was used to evaluate children's well-being and the Strengths and Difficulties Questionnaire (SDQ) was used to evaluate children's internalising-problems. Vulnerable groups were defined as follows: children whose parents had minimal social networks, children from non-traditional families, children of migrant origin or children with unemployed parents. Logistic mixed-effects models were used to assess the associations between social vulnerabilities and psychosocial problems at baseline and follow-up.

After adjusting for classical socioeconomic and lifestyle indicators, children whose parents had minimal social networks were at greater risk of presenting psychosocial problems at baseline $(\mathrm{OR}=1.82 ;[1.38$ $2.41] 99 \% \mathrm{CI})$ and follow-up $(\mathrm{OR}=1.53 ;[1.11-2.11] 99 \% \mathrm{CI})$ as well as those from non-traditional families $(\mathrm{OR}=1.30 ;[1.04-1.63] 99 \% \mathrm{CI})$ compared to non-vulnerable groups.

The highest risk for psychosocial problems was found in children whose parents had minimal social networks (OR=1.97; [1.26-3.08]99\%CI) at both time points. Children with more than 3 vulnerabilities were at more than double the risk of developing psychosocial problems at baseline and follow-up.

Therefore, policy makers should implement measures to strengthen the social support for parents with a minimal social network.

\section{Introduction}

It has been widely acknowledged that disadvantaged socio-economic circumstances are associated with increased health risk $[15,21]$. Socioeconomic status (SES), including family income, parental education, and occupational status, has been associated with a wide range of health, cognitive, and socioemotional outcomes in children, with effects beginning prior to birth and continuing into adulthood [15]. Particularly, children from low SES manifest more behavioural and emotional problems than children from high SES [27]. 
An array of mechanisms linking SES to child well-being have been proposed, with most involving differences in access to material and social resources or reactions to stress-inducing conditions by the children and their parents [5]. Since in most countries inequality and social vulnerabilities have increased during the last two decades, it is important to study the association between social vulnerabilities and psychosocial problems in children [25]. Some studies concluded that parents' social support was beneficial for children's well-being and negatively predicted delinquency across adolescence [13, 37]. Parents' social support allows children to access other support agents, who reduce stress by promoting skills and resiliency $[36,37]$. Children from traditional families had lower risk for high school dropout and teenage pregnancy and had better adult outcomes e.g. fewer socio-emotional as well as higher cognitive scores compared to non-traditional families $[4,6,10]$. Findings on the association between migrant origin and children's mental health were inconsistent with positive, non-significant or negative associations [1, 26, 39]. Concerning unemployment status, children with unemployed parents seemed to have more internalising and externalising problems than those whose parents were both employed [2]. Nevertheless, most of the studies conducted so far are from the United States and focused on classical SES indicators, while other social vulnerabilities (such as children whose parents lack a social network, children from non-traditional families, children of migrant origin and children with unemployed parents) have been less frequently explored in the literature.

Four vulnerable groups will be investigated in the present study: 1) children from non-traditional families, 2) children whose parents lack a social network, 3) children of migrant origin and 4) children with either one or both parents unemployed. These four vulnerable groups seem to have an independent effect from classical SES indicators and interact between them in ways that increase the likelihood of poor health outcomes suggesting cumulative effects [19]. Therefore, the present paper aimed to explore (i) the crosssectional and longitudinal associations between social vulnerabilities and psychosocial problems (poor well-being and internalising problems) in European children participating in the Identification and Prevention of Dietary-and Lifestyle-induced Health Effects in Children and Infants (IDEFICS) Study, (ii) the association between evolution of vulnerabilities over 2-years and psychosocial problems at follow-up and (iii) the association of accumulated vulnerability with psychosocial problems at two time points. Studying these associations will give important insights to understand how disadvantaged socio-economic circumstances in children are associated with increased health risks. 


\section{Materials and methods}

Study population

IDEFICS is a multi-centre prospective cohort study, including a school- and community-based obesity prevention intervention [11] in eight European countries (Belgium, Cyprus, Estonia, Germany, Hungary, Italy, Spain and Sweden). For comprehensive information about IDEFICS, a detailed description is given by Ahrens et al.[3]. 16,228 children aged 2-9 years were examined from September 2007 to June 2008 at baseline (T0). The follow-up (T1) took place two years later (September 2009-June 2010) applying the same standardised assessments where 11,041 children aged 4-11 years were re-examined.

Two different parent proxy-report instruments were employed to assess children's psychosocial problems at baseline and follow-up: the KINDL (Questionnaire for Measuring Health-Related Quality of Life in Children and Adolescents-Revised Version) was used to evaluate children's well-being during the last week and the Strengths and Difficulties Questionnaire (SDQ), a behavioural screening questionnaire, was used in this study for evaluating children's internalising problems over the last 6 months.

\section{Well-being from $K I N D L^{\mathrm{R}}$}

The $\mathrm{KINDL}^{\mathrm{R}}$, a validated instrument for assessing health-related quality of life in children and adolescents, was completed by the parents. The instrument included four of the six original KINDL dimensions: Emotional well-being, Self-esteem, Family relations and Social contacts [7]. Questions on Physical wellbeing and Everyday functioning were excluded in the IDEFICS study. Answers were given according to a 4-point Likert scale (never, rarely, sometimes and often/always) adapted from the original 5-point Likert scale with reversals according to the wording of the question [29]. Scores were summed with higher scores representing more favourable indicators of well-being. The 20th percentile of the total score was taken as threshold to differentiate between children with a poor score (from 0 to 36) and a normal score (from 37 to 48). Although $\mathrm{KINDL}^{\mathrm{R}}$ has been created for those aged 3 years and older, we included children aged 2 years (177 children in total) because those children, to be eligible for IDEFICS participation, were attending pre-schools or kindergartens and then exposed to similar psychosocial factors as their peers. Since analyses excluding these 2-year old children shown similar results, we decided to keep them included. 
The SDQ is a 25-item questionnaire [14] divided in 5 scales (Emotional problems, Conduct problems, Hyperactivity-Inattention behaviour, Peer problems and Prosocial behaviour) and validated for children aged 2-7 years old [30]. Since the IDEFICS study did not incorporate the Hyperactivity scale, only internalising problems (from the Emotional and Peer problems subscales) were included and scored in accordance with published scoring instructions [22]. The scale of internalising problems was dichotomized into a normal score vs. abnormal score according to published cut-offs [22, 23].

\section{Definition of vulnerable groups}

Four vulnerabilities obtained from the parental questionnaire were defined at baseline as our exposures. Social network: Based on the parental response to the question of how many persons they could rely on in case of need including their family: "0-1 person" taken as the vulnerable category and " $\geq 2$ persons" as the non-vulnerable group.

Family structure: If the child did not live with both his/her parents, the family was defined as a "nontraditional family' (including single-parent families, stepparent families, living with grandparents or foster parents or in an institution).

Origin of the parents: A migrant background (vulnerable group) was assumed if one or both parents were born in a country different from where the study took place.

Employment status: If at least one of the parents was unemployed or living on social assistance or welfare, the child was considered as belonging to the vulnerable group.

A total vulnerability score was calculated by adding up the numbers of vulnerabilities a child was exposed to. In all, six vulnerability indicators (minimal social network, non-traditional family, migrant, unemployed, low-income and low-education) were considered. Occupation status was not included as it was highly correlated with employment status. The vulnerability score ranged from 0 (the child had any vulnerability) to 6 (the child had all six vulnerability indicators) and was divided into four categories (three to six vulnerabilities, two vulnerabilities, one vulnerability and no vulnerability).

\section{Lifestyle indicators assessed at baseline:}

Fruit and vegetable consumption was obtained using the food frequency section of Children's Eating Habits Questionnaire-food frequency questionnaire (CEHQ-FFQ) [18]. This FFQ is a self-administered validated screening tool where parents reported usual at-home-consumption frequencies of 42 food items of the 
previous four weeks. The sum of reported intake frequency of fresh fruits, raw and cooked vegetables per week as a healthy diet indicator was calculated.

Physical activity: Parents reported the total weekly hours the children spent playing outdoors and children's participation in sports club activities in the previous month. Physical activity per week was obtained with this formula: [(hours playing outdoors on weekdays $\times 5$ ) + (hours playing outdoors on weekend days $\times 2$ ) + weekly sports participation].

Screen time: Parents reported the daily screen time spent on audio-visual media (TV, video, DVD, computer, game console) by the children for a typical weekday and weekend day. Total screen time per week was calculated as: $(5 \times$ weekday $+2 \times$ weekend $)$.

\section{Weight categories}

Anthropometric measurements were assessed at $\mathrm{T} 0$ according to standardised procedures in all participating countries. Barefoot body height was measured to the nearest $0.1 \mathrm{~cm}$ by trained staff using a portable stadiometer (SECA 225). Body weight in $\mathrm{kg}$ was measured by a child-adapted version of electronic scale TANITA BC-420 SMA with the children weighted in a fasting state and wearing only light clothes. Body mass index (BMI) was calculated by dividing body weight in kilograms by squared body height in metres and then transformed into an age- and sex-specific z-score [8]. Weight groups were categorised using age and sex-specific cut points according to the criteria of the International Obesity Task Force [9].

\section{Classical SES indicators}

Education: parents were asked to indicate the highest level of education of both themselves and their partners. The response categories for each country were coded according to the International Standard Classification of Education (ISCED 1997) and re-categorised into three categories: low (ISCED level 0-2), medium (ISCED level 3-4) and high (ISCED level 5-6) [34]. The highest level of either the mother or the father was taken into account.

Income: parents also provided information on the monthly net income of the household after taxes and deductions responding to nine country-specific categories (1: from the lowest category to 9 : the highest category). The category cut-offs were designed to be country-specific according to a fixed scheme based on the median equivalent income, thus guaranteeing comparability between countries. The results were organised into three categories: low (1-3), medium (4-6) and high income (7-9). 
Occupation: parents were asked to specify their occupational position with 18 possible options, which were later transformed into the three-class version of the European Socioeconomic Classification: working class, intermediate and salariat [16].

The highest level of either the mother or the father was taken into account.

After excluding children with missing values in any of the exposures or outcomes at baseline or follow-up or any of the covariates at baseline, the present analysis finally included 5,987 children (50.6\% boys) (see also Figure 1). Children lost to follow-up were more likely to belong to the high well-being group (82.2\% vs. $75.3 \%$ in the present study) and shown less internalising problems $(82.5 \%$ vs. $85.4 \%)$ than those included in the present study. However, no statistically significant differences were found in social vulnerabilities between children included in this study and those lost at follow-up.

Parents or legal guardians gave written informed consent for examinations and data collection for their children, while children expressed oral consent. Ethical approval was obtained from the research ethics authority of each participating centre.

\section{Statistical analyses}

Logistic mixed-effects models were used to assess the cross-sectional and longitudinal associations between the four dichotomised exposures (social network, family structure, migrant origin and employment status) and each outcome (well-being and internalising problems). The reference category used was the normal (healthy) score for each outcome. All models included a random kindergartens/school and a random country effect to account for the clustered study design.

One cross-sectional and two longitudinal analyses were conducted. In the cross-sectional analysis, predictor and outcome variables from T0 were used. In the first longitudinal analysis, children's well-being and internalising problems at $\mathrm{T} 1$ were related to the T0 exposures. In the second longitudinal analysis, evolution of vulnerability from $\mathrm{T} 0$ to $\mathrm{T} 1$ (vulnerable at T0 and $\mathrm{T} 1$, vulnerable at $\mathrm{T} 0$ and non-vulnerable at $\mathrm{T} 1$, nonvulnerable at T0 and vulnerable at T1; and non-vulnerable at T0 and T1) were related to children's wellbeing and internalising problems at $\mathrm{T} 1$. The patterns of vulnerability were assessed for only three of the vulnerable groups considered since migrant status does not change between baseline and follow-up. Finally, two more analyses were conducted to estimate the accumulation of vulnerability at T0 and psychosocial problems at $\mathrm{T} 0$ and $\mathrm{T} 1$. 
To adjust for possible confounders, two models were run for each analysis: model 1 for each outcome/exposure was adjusted for baseline age, sex and frequency of fruit and vegetable consumption, physical activity, total screen time and BMI z-score and model 2 was additionally adjusted for baseline classical SES indicators (education, income and occupation except for employment status model). For both longitudinal analyses, a variable indicating intervention versus control region was added and models were additionally adjusted for baseline outcomes (well-being and internalising problems at T0, respectively). Before model building, correlations among classical SES indicators were checked resulting in the exclusion of occupation status in models with employment status as main exposure to avoid collinearity problems. The significance level was set at 0.01 to account at least partially for multiple testing. The analyses were performed using the Statistical Package for the Social Sciences (version 22.0; SPSS, Inc.).

\section{Results}

Table 1 summarises the distributions of predictors and background variables for the two outcomes (wellbeing and internalising problems) at $\mathrm{T} 0$ and $\mathrm{T} 1$. For the continuous covariates, the median is shown. Table 2 presents odds ratios (OR), 99\% confidence intervals (CI) and p-values for the models assessing the cross-sectional and longitudinal associations between the four vulnerability indicators and well-being and internalising problems at baseline and after two-year follow up. After adjusting for lifestyle indicators and the classical SES indicators (full adjustment model 2), those children whose parents had minimal social networks $(\mathrm{OR}=1.82 ;[1.38-2.41] 99 \% \mathrm{CI})$ at $\mathrm{T} 0$ and $\mathrm{T} 1$ and non-traditional families $(\mathrm{OR}=1.30 ;[1.04-$ 1.63]99\% CI) at T0 were more likely to have a poor well-being than those with no vulnerabilities at T0. Similarly, there was a higher likelihood of internalising problems in children with minimal social network parents at $\mathrm{T} 0(\mathrm{OR}=1.51 ;[1.12-2.03] 99 \% \mathrm{CI})$ and $\mathrm{T} 1(\mathrm{OR}=1.53 ;[1.11-2.11] 99 \% \mathrm{CI})$ compared to those nonvulnerable. No statistically significant associations were observed for the other groups but associations still pointed to the expected directions.

Table 2 presents odds ratios (OR), 99\% confidence intervals (CI) and p-values for the models assessing the cross-sectional associations between the four vulnerability indicators and well-being and internalising problems at T0 (basic and fully adjusted models). In model 3 (full adjustment), those children whose parents had minimal social networks (OR 1.82, [1.38; 2.41] 99\%CI) and non-traditional families (OR 1.30, [1.04; 1.63] 99\%CI) were more likely to have a poor well-being than those with no vulnerabilities at T0. Similarly, there was a higher likelihood of internalising problems in children with minimal social network parents 
(OR 1.51, [1.12; 2.03] 99\%CI) compared to those non-vulnerable at T0. No statistically significant associations were observed for the other groups but associations still pointed to the expected directions.

Table 3 displays the results for the associations between the patterns of vulnerability evolution over time and well-being and internalising problems at T1. In model 2, those children whose parents reported to have a minimal social network just at $\mathrm{T} 1(\mathrm{OR}=1.95 ;[1.40 ; 2.71] 99 \% \mathrm{CI})$ or at two time points $(\mathrm{OR}=1.57,[1.06$; $2.33] 99 \% \mathrm{CI})$ as well as children from non-traditional families $(\mathrm{OR}=1.28 ;[1.00-1.65] 99 \% \mathrm{CI})$ were more likely to have a poor well-being than those who were non-vulnerable at two time points. Likewise, there was a higher likelihood of internalising problems in children whose parents reported to have a minimal social network at two time points $(\mathrm{OR}=1.97 ;[1.26-3.08] 99 \% \mathrm{CI})$ and those children from non-traditional families just at $\mathrm{T} 1(\mathrm{OR}=1.60 ;[1.07-2.39] 99 \% \mathrm{CI})$ compared to those who were non-vulnerable at two time points.

Table 4 shows the association between the accumulation of vulnerabilities assessed at baseline and wellbeing and internalising problems at T0 and T1. A higher number of vulnerabilities was associated with a higher likelihood of having psychosocial problems in both T0 and T1, where the OR increased with the number of present vulnerabilities: one vulnerability $(\mathrm{OR}=1.30 ;[1.03-1.64] 99 \% \mathrm{CI})$; two vulnerabilities $(\mathrm{OR}=1.81 ;[1.38-2.37] 99 \% \mathrm{CI})$ and three to six vulnerabilities $(\mathrm{OR}=2.63 ;[1.86-3.73] 99 \% \mathrm{CI})$.

\section{Discussion}

The importance of SES for health is well established but there is a lack of research determining the impact of SES and interrelated factors such as vulnerable groups on psychosocial problems in European children $[17,32]$. We investigated the association between belonging to a vulnerable (vs. non-vulnerable) group and psychosocial problems (poor well-being and internalising problems) over a two-year period in children aged 2 to 9 years old participating in a European study. This research found that children whose parents had minimal social networks and children from non-traditional families had a higher likelihood of presenting psychosocial problems cross-sectionally and longitudinally compared to non-vulnerable groups. The findings of our study are in line with previous research despite some differences. Several studies have explored the relationship between different socioeconomic and cultural factors and psychosocial problems 
$[12,31,41]$. A systematic review shown that socioeconomically disadvantaged children were two to three times more likely to develop mental health problems [31].

In our study, migrant status was not significantly associated with a higher risk of having psychosocial problems. This is in accordance with some investigations [24, 35, 40], although other studies found that migrant children fare worse compared to their native peers in relation to mental health [2, 20]. However, studies varied with the informants used and the characteristics of the migrant group and the host country. Concerning social network, we found a statistically significant association between children whose parents reported to have a minimal social network with a higher risk of having psychosocial problems; which is in agreement with previous studies that associated parents' minimal social networks and children's behavioural disturbance $[13,33,37]$.

Regarding family structure, children from non-traditional families had a higher risk of having psychosocial problems than those children from traditional families. These results confirmed previous investigations that concluded children from traditional families had fewer socio-emotional and higher cognitive scores than those from non-traditional families [10, 38].

Concerning parental unemployment, we did not find a statistically significant association with children's psychosocial problems when controlling for classical SES indicators. This finding contradicted partly the conclusions of Powdthavee and Vernoit (2013) who found that parental job loss had a positive influence on young children's well-being [28].

Some limitations of this study should be acknowledged. Firstly, the IDEFICS study is not representative neither of the European population nor of the countries participating since each survey centre covered a limited geographic area within a country. Secondly, some groups (from the lowest or the highest SES) could be underestimated as participation in this study was voluntary and usually these populations are less likely to take part in research. Likewise, a selection bias cannot be precluded because some participants (with lower well-being score and more internalising problems) did not complete all required information or did not continue the study at follow-up. Finally, migrant origin and reasons for migration may differ significantly from one person to another and consequently some groups of migrants could be more vulnerable than others. However, due to the small size of some migrant groups, no group differences were taken into account in the present investigation. 
A special strength of the study is that to our knowledge, previous research has not investigated the association between vulnerabilities such as social network, family structure and unemployment status with psychosocial problems in a longitudinal study. A large sample size including children from eight different countries following standardised procedures and using validated instruments, is also a strength of our study.

\section{Conclusions}

The current study suggests associations between social vulnerabilities and psychosocial problems (poor well-being and internalising problems), independent of family income, parental occupation, parental education and lifestyle indicators. Mainly having parents with minimal social network and the lack of a traditional family structure were disadvantageous. Interventions during the early years of a child's life may be needed to reduce inequalities and counteract negative effects on children's mental health. Therefore, policy makers should implement measures to strengthen the social support for parents with a minimal social network.

\section{Acknowledgements}

This work has been done as part of the IDEFICS Study (http://www.idefics.eu). The authors gratefully acknowledge the financial support of the European Community within the Sixth RTD Framework Programme Contract No. 016181 (FOOD). I. I has been financed by the FPU (grant reference FPU014/00922) Predoctoral Programs (Spanish Ministry of Education and Science). We thank the IDEFICS children and their parents who generously volunteered and participated in this project.

The authors' contributions were as follows: I. I carried out the statistical analysis and drafted the manuscript along with N. M. C. B. designed the statistical analyses. K. B., J. M. F.-A., W. G., R. F., B.T., and P.R. developed the measurement instruments; L. R., S. D. H., M. H., L. A. M., and T. V. supervised the national data collection authors read and critically reviewed the manuscript.

\section{Conflict of interest Statement}

The authors declare that there are no conflicts of interest.

\section{References}

1. Acevedo-Garcia D, Pan J, Jun HJ, Osypuk TL, Emmons KM (2005) The effect of immigrant generation on smoking. Soc Sci Med 61:1223-1242 
2. Agnafors S, Sydsjo G, Comasco E, Bladh M, Oreland L, Svedin CG (2016) Early predictors of behavioural problems in pre-schoolers - a longitudinal study of constitutional and environmental main and interaction effects. BMC Pediatr 16:76

3. Ahrens W, Bammann K, Siani A, Buchecker K, De Henauw S, Iacoviello L, Hebestreit A, Krogh V, Lissner L, Marild S, Molnar D, Moreno LA, Pitsiladis YP, Reisch L, Tornaritis M, Veidebaum T, Pigeot I (2011) The IDEFICS cohort: design, characteristics and participation in the baseline survey. Int J Obes (Lond) 35 Suppl 1:S3-15

4. Anderson J (2014) The impact of family structure on the health of children: Effects of divorce. Linacre Q 81:378-387

5. Bradley RH, Corwyn RF (2002) Socioeconomic status and child development. Annu Rev Psychol 53:371-399

6. Brown SL, Manning WD, Stykes JB (2015) Family Structure and Child WellBeing: Integrating Family Complexity. J Marriage Fam 77:177-190

7. Bullinger M, Brutt AL, Erhart M, Ravens-Sieberer U (2008) Psychometric properties of the KINDL-R questionnaire: results of the BELLA study. Eur Child Adolesc Psychiatry 17 Suppl 1:125-132

8. Cole TJ, Freeman JV, Preece MA (1998) British 1990 growth reference centiles for weight, height, body mass index and head circumference fitted by maximum penalized likelihood. Stat Med 17:407-429

9. Cole TJ, Lobstein T (2012) Extended international (IOTF) body mass index cutoffs for thinness, overweight and obesity. Pediatr Obes 7:284-294

10. Craigie T-A, Brooks-Gunn J, Waldfogel J (2010) Family Structure, Familiy Stability and Early Child Wellbeing. In:Princeton University

11. De Henauw S, Verbestel V, Marild S, Barba G, Bammann K, Eiben G, Hebestreit A, Iacoviello L, Gallois K, Konstabel K, Kovacs E, Lissner L, Maes L, Molnar D, Moreno LA, Reisch L, Siani A, Tornaritis M, Williams G, Ahrens W, De Bourdeaudhuij I, Pigeot I (2011) The IDEFICS community-oriented intervention programme: a new model for childhood obesity prevention in Europe? Int J Obes (Lond) 35 Suppl 1:S16-23

12. de Laat SA, Essink-Bot ML, van Wassenaer-Leemhuis AG, Vrijkotte TG (2016) Effect of socioeconomic status on psychosocial problems in 5- to 6-year-old preterm- and term-born children: the ABCD study. Eur Child Adolesc Psychiatry 25:757-767

13. Ghazarian SR, Roche KM (2010) Social support and low-income, urban mothers: longitudinal associations with adolescent delinquency. J Youth Adolesc 39:10971108

14. Goodman R (1997) The Strengths and Difficulties Questionnaire: a research note. J Child Psychol Psychiatry 38:581-586

15. Gupta RP, de Wit ML, McKeown D (2007) The impact of poverty on the current and future health status of children. Paediatr Child Health 12:667-672

16. Harrison E, Rose D (2006) The european socio-economic classification (ESeC) user guide. In:University of Essex, Colchester

17. Hattgen K, Klasen S (2008) Well-being of Migrant Children and Migrant Youth in Europe. In:

18. Huybrechts I, Bornhorst C, Pala V, Moreno LA, Barba G, Lissner L, Fraterman A, Veidebaum T, Hebestreit A, Sieri S, Ottevaere C, Tornaritis M, Molnar D, Ahrens W, De Henauw S (2011) Evaluation of the Children's Eating Habits Questionnaire used in the IDEFICS study by relating urinary calcium and 
potassium to milk consumption frequencies among European children. Int J Obes (Lond) 35 Suppl 1:S69-78

19. Iguacel I, Fernandez-Alvira JM, Bammann K, De Clercq B, Eiben G, Gwozdz W, Molnar D, Pala V, Papoutsou S, Russo P, Veidebaum T, Wolters M, Bornhorst C, Moreno LA (2016) Associations between social vulnerabilities and dietary patterns in European children: the Identification and prevention of Dietary- and lifestyle-induced health EFfects In Children and infantS (IDEFICS) study. Br J Nutr 116:1288-1297

20. Leavey G, Hollins K, King M, Barnes J, Papadopoulos C, Grayson K (2004) Psychological disorder amongst refugee and migrant schoolchildren in London. Soc Psychiatry Psychiatr Epidemiol 39:191-195

21. McLoyd VC (1998) Socioeconomic disadvantage and child development. Am Psychol 53:185-204

22. Mind Yi (2009) Information for researchers and professionals about the Strengths and Difficulties Questionanaire. In:

23. Mind Yi (2009) Strengths and Difficulties Questionnaire: information for researchers and professionals about the Strenghts and Difficulties Questionnaire. In:

24. Molcho M, Cristini F, Gabhainn S, Santinello M, Moreno C, Gaspar de Matos M, Bjarnason T, Baldassari D, Due P (2010) Health and well-being among child inmigrants in Europe. In:Eurohealth, p 20-23

25. OECD (2011) An Overview of Growing Income Inequalities in OECD Countries: Main Findings. In:

26. Pantzer K, Rajmil L, Tebe C, Codina F, Serra-Sutton V, Ferrer M, RavensSieberer U, Simeoni MC, Alonso J (2006) Health related quality of life in immigrants and native school aged adolescents in Spain. J Epidemiol Community Health 60:694-698

27. Potijk MR, de Winter AF, Bos AF, Kerstjens JM, Reijneveld SA (2015) Behavioural and emotional problems in moderately preterm children with low socioeconomic status: a population-based study. Eur Child Adolesc Psychiatry 24:787-795

28. Powdthavee N, Vernoit J (2013) Parental unemployment and children's happiness: A longitudinal study of young people's well-being in unemployed households. Labour Econ 24:253-263

29. Ravens-Sieberer U, Bullinger M (1998) Assessing health-related quality of life in chronically ill children with the German KINDL: first psychometric and content analytical results. Qual Life Res 7:399-407

30. Ravens-Sieberer U, Erhart M, Gosch A, Wille N (2008) Mental health of children and adolescents in 12 European countries-results from the European KIDSCREEN study. Clin Psychol Psychother 15:154-163

31. Reiss F (2013) Socioeconomic inequalities and mental health problems in children and adolescents: a systematic review. Soc Sci Med 90:24-31

32. Rijlaarsdam J, Stevens GW, van der Ende J, Hofman A, Jaddoe VW, Mackenbach JP, Verhulst FC, Tiemeier H (2013) Economic disadvantage and young children's emotional and behavioral problems: mechanisms of risk. J Abnorm Child Psychol 41:125-137

33. Samuelsson MA (1994) Associations between the mental health and social networks of children and parents in single-parent families. A comparison between a clinical group and a control group. Acta Psychiatr Scand 90:438-445 
34. Statistics. UNESaCOUIf (1997) International Standard Classification of Education (ISCED). In, UNESCO: Montreal, QC, 2006

35. Stevens GW, Vollebergh WA (2008) Mental health in migrant children. J Child Psychol Psychiatry 49:276-294

36. Taylor ZE, Conger RD, Robins RW, Widaman KF (2015) Parenting Practices and Perceived Social Support: Longitudinal Relations with the Social Competence of Mexican-origin Children. J Lat Psychol 3:193-208

37. Thompson RA, Flood MF, Goodvin R (2015) Social Support and Developmental Psychopathology. In:John Wiley \& Sons, Inc., p 1-37

38. Vanaelst B, De Vriendt T, Ahrens W, Bammann K, Hadjigeorgiou C, Konstabel K, Lissner L, Michels N, Molnar D, Moreno LA, Reisch L, Siani A, Sioen I, De Henauw S (2012) Prevalence of psychosomatic and emotional symptoms in European school-aged children and its relationship with childhood adversities: results from the IDEFICS study. Eur Child Adolesc Psychiatry 21:253-265

39. Vieno A, Santinello M, Lenzi M, Baldassari D, Mirandola M (2009) Health status in immigrants and native early adolescents in Italy. J Community Health 34:181187

40. Vollebergh WA, ten Have M, Dekovic M, Oosterwegel A, Pels T, Veenstra R, de Winter A, Ormel H, Verhulst F (2005) Mental health in immigrant children in the Netherlands. Soc Psychiatry Psychiatr Epidemiol 40:489-496

41. Woodhead M, Dornan P, Murray H, Lives Y (2012) What Inequality Means for Children: Evidence from Young Lives. In: 